\title{
Migration and risk of psychosis in the Canadian context
}

\author{
James B. Kirkbride PhD, Anna-Clara Hollander PhD
}

See also www.cmaj.ca/lookup/doi/10.1503/cmaj.141420

$\mathrm{S}$ everal migrant groups and their direct descendants face a substantially increased risk of schizophrenia and other psychotic disorders, ${ }^{1}$ primarily evidenced by well-conducted epidemiologic studies from Europe..$^{2-4}$ This risk may be even greater among refugees. There is a dearth of epidemiologic research involving refugees, ${ }^{5}$ despite the United Nation's estimate that the number of refugees worldwide has reached 16.7 million, the highest figure since 1996 (partly due to the humanitarian crisis in Syria). Until now, it has been unclear whether immigrants to Canada, including refugees, experience similar increased levels of psychotic disorders as those observed among many black and minority ethnic groups in Europe. In a linked research paper, Anderson and colleagues $^{6}$ present new data that shed light on these important issues.

Reliable data from a Canadian context are vital for two reasons. First, Canada's migration policy, based on a model of human capital, sees roughly a quarter of a million people arrive and settle each year on economic or humanitarian grounds. ${ }^{6}$ Like all people, these groups require timely and appropriate access to mental health services, although this is not currently guaranteed. ${ }^{7}$ Health care policy makers need to be prepared for both the level and form of any additional need from migrant groups. Second, Canadian data on risk among migrant groups can inform international efforts to identify etiologic factors in the genesis of schizophrenia and other psychotic disorders. Differing patterns of migration to Canada compared with European countries allow an opportunity to examine the distribution of both etiologic and confounding factors to which migrants and their direct descendants in different settings may have been exposed.

Using linked administrative records of more than four million people aged 14-40 years living in the province of Ontario (home to the largest proportion of first-generation migrants in Canada), Anderson and colleagues ${ }^{6}$ constructed a retrospective cohort, followed over 10 years or until the first diagnosis of schizophrenia or a schizoaffective disorder. Incidence rates were compared between first-generation migrants, refugees and the general population, with adjustments for age and sex.
The authors observed higher rates of psychotic disorders in refugees from East Africa and South Asia (95\% and 51\% increased risk, respectively) than in the general population. ${ }^{6}$ However, refugees from other regions of the world were not observed to have an increased risk, although power to detect these effects with the small samples available may have precluded such observation. Future efforts to replicate these findings using larger samples of refugees are required, and may also permit detection of the potential pre- and postmigration factors relevant to risk. In addition to exposure to traumatic events before migration, refugees may continue to endure social, cultural and economic hardships ${ }^{8}$ following migration, which may increase risk, including stresses induced by the asylum process itself.

Perhaps the most striking finding from the study is that rates of psychosis were not elevated consistently among nonrefugee first-generation migrants relative to the general population. Indeed, Anderson and colleagues ${ }^{6}$ observed significantly lower incidence rates among migrants from East Asia and most parts of Europe relative to Ontario's general population. Only first-generation migrants from the Caribbean and Bermuda had an elevated risk (60\% higher incidence). The direction of this latter effect will be of little surprise to readers familiar with the epidemiology of schizophrenia, but the magnitude of the excess might. A recent meta-analysis of schizophrenia incidence in the black Caribbean population in the United Kingdom placed the risk at almost five times greater than in the reference (usually white) population. ${ }^{9}$ Such excess does not appear to be explained by selective migration, ${ }^{10}$ misdiagnosis
Competing interests: None declared.

This article was solicited and has not been peer reviewed.

Correspondence to: James Kirkbride, j.kirkbride@ucl.ac.uk CMAJ 2015. DOI:10.1503 /cmaj.150494 
of mood disorders ${ }^{4}$ or confounding by socioeconomic position. ${ }^{4}$

The lower excess risk among migrants in a Canadian context may have several possible explanations. Canada's immigration policy requires potential migrants to pass a medical examination before emigration, which may lead to a "healthy immigrant effect," whereby migrants, on average, are healthier than the general population. Canada's immigration policy further favours younger, more highly skilled, and English- or French-speaking applicants who may be able to settle, adapt and integrate more quickly on arrival. Here, Canada's diverse ethnic and migration history in the general population may also be relevant to concepts of risk and resilience for mental health disorders. Unlike many European settings where one ethnic group forms a predominant majority, Canada's relative population diversity may allow new immigrants to more quickly and easily establish social and economic support networks. This may convey a protective effect from social adversities often experienced following migration, including isolation, deprivation or discrimination. This may not always have been the case, however. One historical, retrospective study of European migrants to Canada at the beginning of the 20th century found elevated rates of schizophrenia among first-generation immigrants relative to the Canadian-born population. ${ }^{11}$

A further alternative explanation for the lower risk of psychosis observed by Anderson and colleagues among first-generation immigrants relative to the general population is higher-than-usual schizophrenia incidence in the general (reference) population studied. Owing to limitations of the administrative databases available to the authors, their reference population comprised all people born in Canada, which included a proportion of black and minority ethnic groups, who would be expected to show elevated psychosis rates, given data from other settings. ${ }^{1}$ Furthermore, the reference group includes first-generation immigrants who initially migrated to provinces other than Ontario, and any first-generation migrants arriving before 1985 (when Citizenship and Immigration Canada's records began). The data support this possibility; the crude incidence of schizophrenia and schizoaffective disorder in the study's reference population was nearly 56 new cases per 100000 person-years. This estimate is 1.5-4 times greater than the crude incidence for reference populations reported in other countries, including the white British in the $\mathrm{UK}^{4}$ the white Dutch in the Netherlands, ${ }^{3}$ and native Danish $^{2}$ and Swedish ${ }^{5}$ populations, even when a national register-based cohort design is employed. ${ }^{2.5}$

This matters for Canadian public mental health policy because high and potentially heterogeneous risk of psychotic illness in the general population also needs adequate resourcing. Empirically, we know such need will vary by factors including migrant status, ethnicity, age, sex and socioeconomic position. The linked study highlights the essential need to provide routine data of sufficient quality and detail for the precise estimation of incidence and prevalence of psychotic disorders among all subgroups of the general population. ${ }^{12}$ It is only on the foundation of robust epidemiologic estimates of incidence of psychiatric distress that the vital care provided through clinical services and public mental health policy can be optimized to promote better mental health and well-being for all residents in Canada, including first-generation immigrants and refugees.

\section{References}

1. Bourque F, van der Ven E, Malla A. A meta-analysis of the risk for psychotic disorders among first- and second-generation immigrants. Psychol Med 2011;41:897-910.

2. Cantor-Graae E, Pedersen CB. Risk of schizophrenia in secondgeneration immigrants: a Danish population-based cohort study. Psychol Med 2007;37:485-94.

3. Veling W, Selten JP, Veen N, et al. Incidence of schizophrenia among ethnic minorities in the Netherlands: a four-year firstcontact study. Schizophr Res 2006;86:189-93.

4. Kirkbride JB, Barker D, Cowden F, et al. Psychoses, ethnicity and socio-economic status. Br J Psychiatry 2008;193:18-24.

5. Leão TS, Sundquist J, Frank G, et al. Incidence of schizophrenia or other psychoses in first- and second-generation immigrants: a national cohort study. J Nerv Ment Dis 2006;194:27-33.

6. Anderson KK, Cheng J, Susser E, et al. Incidence of psychotic disorders among first-generation immigrants and refugees in Ontario. CMAJ 2015; May 11 [Epub ahead of print].

7. Simich L, Beiser M. Immigrant and refugee mental health in Canada: lessons and prospects. In: Bhugra D, Gupta S, editors. Migration and mental health. Cambridge (UK): Cambridge University Press; 2010.

8. Simich L, Hamilton H, Baya BK. Mental distress, economic hardship and expectations of life in Canada among Sudanese newcomers. Transcult Psychiatry 2006;43:418-44.

9. Tortelli A, Errazuriz A, Croudace T, et al. Schizophrenia and other psychotic disorders in Caribbean-born migrants and their descendants in England: systematic review and meta-analysis of incidence rates, 1950-2013. Soc Psychiat Epidemiol 2015 Feb. 7 [Epub ahead of print].

10. van der Ven E, Dalman C, Wicks S, et al. Testing Ødegaard's selective migration hypothesis: a longitudinal cohort study of risk factors for non-affective psychotic disorders among prospective emigrants. Psychological Medicine 2014;45:727-34.

11. Smith GN, Boydell J, Murray RM, et al. The incidence of schizophrenia in European immigrants to Canada. Schizophr Res 2006;87:205-11

12. Kirkbride JB, Jones PB. Parity of esteem begins at home: translating empirical psychiatric research into effective public mental health. Psychol Med 2014;44:1569-76.

Affiliations: PsyLife Group (Kirkbride), Division of Psychiatry, University College London, London, UK; Department of Public Health Sciences (Hollander), Karolinska Institutet, Stockholm, Sweden

Contributors: Both authors contributed to the concept of the commentary. James Kirkbride drafted the manuscript, with critical input on aspects of refugee migration contributed by AnnaClara Hollander. Both authors approved the final version to be published and agreed to act as guarantors of the work.

Acknowledgements: James Kirkbride is supported by a Sir Henry Dale Fellowship jointly funded by the Wellcome Trust and the Royal Society. Anna-Clara Hollander is funded by FORTE: The Swedish Research Council for Health, Working Life and Welfare. The funders had no involvement in the preparation of this manuscript. 